Contents List available at RAZI Publishing

Environment \& Ecosystem Science (EES)

Journal Homepage: http://www.razipublishing.com/journals/environment-and-ecosystem https://doi.org/10.26480/ees.01.2017.23.27

\title{
The Practice, Challenges and Awareness of Residential Solid Waste Management in the City of Al -Marj, Libya
}

\author{
Jaouda R. Jaouda Hamad ${ }^{1}$, Marlia M. Hanafiah ${ }^{1,2},{ }^{*}$, Akbar John, B ${ }^{3}$. Hassan I. Sheikh ${ }^{3}$
}

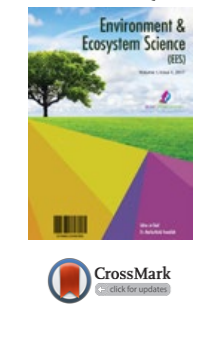

${ }^{1}$ School of Environmental and Natural Resource Sciences, Faculty of Science and Technology, Universiti Kebangsaan Malaysia, 43600 UKM Bangi, Selangor, Malaysia. ${ }^{2}$ International Water, Air \& Soil Conservation Society, 59200 Kuala Lumpur, Malaysia

${ }^{3}$ Institute of Oceanography and Maritime Studies (INOCEM), ${ }^{4}$ Department of Biotechnology, Kulliyyah of Science, International Islamic University Malaysia (IIUM), Kuantan, Pahang, International Islamic University Malaysia (IIUM), Kuantan, Pahang.

${ }^{*}$ Corresponding author. Tel.: +60389215865; Fax.: +60389253357

This is an open access article distributed under the Creative Commons Attribution License, which permits unrestricted use, distribution, and reproduction in any medium, provided the original work is properly cited.

\section{ARTICLE DETAILS}

Article history:

Received 27 September 2016 Accepted 13 December 2016 Available online 10 January 2017

\section{Keywords:}

Solid Waste, Main Constraints, Recycling, Awareness, Al Marj City.

\section{ABSTRACT}

Solid waste management (SWM) in urban cities has always been a challenge to municipalities. Piles of garbage are seen on the roads and suburbs of highly populated neighbourhoods in the city of Al Marj, Libya. This study aimed at identifying the factors and barriers which influence solid waste management (SWM) in the city of Al Marj, Libya. The data was collected via a questionnaire survey and interview sessions with the residents of the city. A total of 700 questionnaires were distributed randomly; only 482 of these were filled up and returned. The results showed that the city of Al-Marj has a profound solid waste management and awareness problems that must be tackled immediately. The local authorities in charge of the SWM seemed to lack experience as well as facilities required for proper solid waste management. The residents also showed lack of awareness on recycling solid waste, however, they agreed to its importance. The over finding of the study indicated that numerous factors led to the solid waste management problem in the city of Al Marj, Libya.

\section{INTRODUCTION}

The solid waste management in most urban cities has developed as one of the most challenging situation confronting the natural security in most of developing nations. In addition, Libya has different structures solid waste which is different with other counties namely in the composition, density, political, economic framework, and waste amount access to waste collection, awareness, and attitude. Nowadays, (SWM) conditions in developing countries are usually a bit horrific reminded of those found in the developed world long time ago. Therefore, solid-waste management is a multidimensional issue that incorporates political, institutional, social, culture, technical and economic aspects. Enhancing SWM in developing world obliges endeavours to raise public awareness, increase funding, build expertise, and invest in infrastructure [1]. Many researchers have argued that the waste problem is caused by human behaviour and therefore the solution lies in changing that behaviour [2]. Ineffective waste collection and the absence of disposal facilities are the normal issue in developing nations due to of the absence of assets to buy progressed and costly advances to bolster squander administration exercises, developing nations are more influenced then developed nations [3]. This paper sets out to present an indepth study aimed at highlighting the constraints of residential solid waste and barriers that discourages residents from recycling in the city of al -Marj in Libya.

The term solid waste management has been defined differently by different writers and authorities. For example, the Sanitation Connection [4] defines it as all activities that seek to minimize the health, environmental and aesthetic impacts of solid wastes. In a developing country framework, though solid waste management accounts for $20-50 \%$ of the municipal budget [5, 6] the service is provided to only about $50 \%$ of the urban population; actual collection only accounts for around $60-70 \%$ the refuse [7, 8]. For instance, Latin American countries were generating approximately 275,000 tons of solid waste per day in urban areas, necessitating a fleet of 30,000 trucks and $350,000 \mathrm{~m} 3$ of land a day to properly collect and dispose the waste [9]. The insufficiency of services results in the deterioration of the urban environment in the form of water, air, and land pollution; which not only poses risks to human health but to the environment as well [10]. Moreover in most developing countries, there is lack of human resources and technical expertise both at national and local levels so that was the main reason for lack of comprehensive waste management planning in developing countries [11]. SWM is given low priority in developing countries; as a result, very limited funds are allocated to the sector by government. This problem is acute at the local government level where local revenue collection system is inadequately developed and financial base for public service including SWM is weak [12]. On the other hand, the lack of effective legislation for solid waste management, which is a norm in most developing countries, is partially responsible for the roles functions of the relevant national agencies not being clearly defined and the lack of coordination among them [11]. Therefore, further added that, solid waste collection schemes of cities in the developing world generally serve only a limited part of the urban population. The people remaining without waste collection services are usually the low-income population living in peri-urban areas. According to him, one of the main reasons is the lack of financial resources to cope with the increasing amount of generated waste produced by the rapid growing cities [13]. At study conducted by [11] conducted the social status of SWM workers is generally low both in developed and developing countries, but more severe in developing countries than developed countries. In addition, public awareness and attitudes to waste can affect the whole solid waste management system [13]. Reusing is more efficient and better than recycling and composting methods because cleaning and reusing materials in their present form avoids the cost of energy for remaking them in to something else [14]. In other study by Vencatasawmy et al. [15] found that recycling behaviour of family units in Kiruna city in Sweden. In this manner, we have to build our comprehension of strong solid waste management attributes to empower the advancement of other bolster apparatuses to upgrade the SWM. Table 1 shows several arguments from scholars regarding to SWM. The amount and composition of waste generated in Al-Marj City has increased due to the inadequate investment in collection, transport, and treatment facilities. These problems are further exacerbated by political, economic and social conditions in the city. The average generation in Al Marj is $1.09 \mathrm{~kg}$ per person per day, which is higher than the average generation in the capital city of Libya, Tripoli (1.0 kg per person per day) [16]. Meanwhile, it is similar to the average generating rate in of the majority of Arabic cities, which is roughly calculated to be around (1.04 kg per person per day) [16]. However, in comparison, the range of generation rate in Al Marj city was higher than the per capita solid waste generation rate in Tehran in 2005 which was $0.88 \mathrm{~kg}$ per person per day [17] and was $0.86 \mathrm{~kg}$ per person in Santiago de Cuba, and lower than the per capita solid waste generation rate in China which was $1.21 \mathrm{~kg}$ per person per day [18] and almost similar to 1 kg per person day in Gümüşhane in Turkey [19] and also similar to $1 \mathrm{~kg}$ per person day in Penang, Malaysia [20]. Generation has been influenced by the time and seasons of the year, local culture, traditions and personal income. The quantities of waste accumulated and transported by the operators of sanitation services have gone up and down following the season, the number of the population (especially during holidays), to the collecting frequency and last but not the least, to the passing of the beneficiaries from one operator to another. 
Table 1: Sub-categories of the five presented factors from different scholars.

\begin{tabular}{|c|c|c|}
\hline $\begin{array}{l}\text { Author/ } \\
\text { reference }\end{array}$ & Sub-categories & Categories \\
\hline $\begin{array}{l}\text { Ogawa, } \\
\text { [11] }\end{array}$ & $\begin{array}{l}\text { 1. lack of human resources } \\
\text { 2. weakness of waste of both planning and operation } \\
\text { of management process } \\
\text { 3. lack of overall plans for waste management } \\
\text { 4. The lack of research and development activities in } \\
\text { developing countries }\end{array}$ & $\begin{array}{l}\text { Technical } \\
\text { Constraints }\end{array}$ \\
\hline $\begin{array}{l}\text { Gebrie } \\
{[12]}\end{array}$ & $\begin{array}{l}\text { 1. limited funds for waste management sector } \\
\text { 2. lack of good financial management and planning } \\
\text { 3. users' ability to pay for the services and their } \\
\text { willingness to pay for the services }\end{array}$ & $\begin{array}{l}\text { Economic } \\
\text { Constraints }\end{array}$ \\
\hline $\begin{array}{c}\text { Zurbrugg. } \\
\text { [13] }\end{array}$ & $\begin{array}{l}\text { 1. no clear roles/functions of the various national } \\
\text { agencies defined in relation to waste management } \\
\text { 2. The lack of coordination } \\
\text { 3. The lack of effective legislation for waste } \\
\text { management }\end{array}$ & $\begin{array}{l}\text { Institutional } \\
\text { Constraints }\end{array}$ \\
\hline $\begin{array}{l}\text { Ogawa, } \\
\text { [11] }\end{array}$ & $\begin{array}{l}\text { 1. solid waste management workers are generally low } \\
\text { in developing countries } \\
\text { 2. insufficient resources avalable in the government } \\
\text { sector }\end{array}$ & $\begin{array}{c}\text { Social } \\
\text { Constraints }\end{array}$ \\
\hline $\begin{array}{c}\text { Zurbruge. } \\
\text { [13] }\end{array}$ & $\begin{array}{l}\text { 1. lack of public awareness } \\
\text { 2. no much willingness to pay for waste management } \\
\text { services }\end{array}$ & $\begin{array}{l}\text { culture } \\
\text { Constraints }\end{array}$ \\
\hline
\end{tabular}

\section{METHODOLOGY}

2.1 Study area

The study area in this paper is Al Marj city in Libya which is located in north-eastern of Libya and lies on the bank of the Mediterranean Sea shows in figure (1). The regulatory seat of Al-Marj city was known as Barca. AlMarj is arranged on the Cyrenaica level at the western edge of Jebel Akhdar and has an expected populace of 85,315 starting 2012 with coordination: $32^{\circ} 29^{\prime} 12^{\prime \prime} \mathrm{N} 20^{\circ} 50^{\prime} 02^{\prime \prime} \mathrm{E}$.

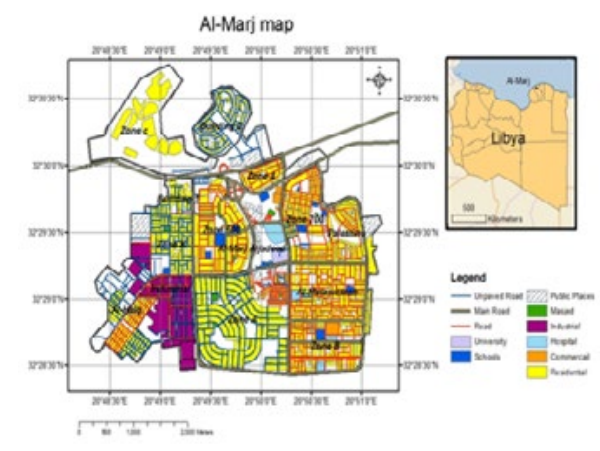

Fig 1. The Four Regions of Al-Mari City.

\subsection{Survey and questionnaire design}

The survey was conducted using direct face to face interviews to the households in selected neighbourhoods in Al Marj city in Libya. Out of 700 questionnaires sent out to the residents, only 482 questionnaires were returned and analysed, yielding a response rate of $69 \%$ the questionnaires for each area were distributed among 3 different income groups (i.e., high, middle, and low income groups). The questionnaires were first written in English and were later translated to Arabic. The reasons for writing the questionnaire in Arabic include the fact that the majority of the city residents do not understand English and in order to avoid any biased views on the returned questionnaires. These questionnaires were randomly distributed in four regions of Al-Marj city (east, west, south, and north) see Figure (2). Data collection was done from January 8, 2012 to November 11, 2012.

\section{RESULTS AND DISCUSSIONS}

\subsection{Background of the Respondents}

Out of the 700 questionnaires were distributed, 482 questionnaires were returned and analysed. The respondents' information was categorized based on their demographic background (Table 2). Almost all of the respondents were Libyan (92.3\%) compared to other ethnics (7.7\%). The respondents were from various ages, under 20 years old (14.1\%), 21 to 29 (38\%), 30 to $39(34.2 \%), 40$ to $49(10.2 \%), 50$ to $59(2.9 \%)$ and above 60 years old $(0.6 \%)$. Among them, $54.8 \%$ were male and $45.2 \%$ were female. Majority of the respondents had a university level qualification (72.4\%). About $35.1 \%$ of the respondents were government servant, $4.8 \%$ were in the private sector, $7.1 \%$ were entrepreneurs, while the rest (53.1\%) were unemployed (housewife, students and unemployed). As most of them were unemployed, $46.7 \%$ did not have any income. Only $26.3 \%$ of them earned more than LYD600/month. More than half of the respondents stay in apartment (63.7\%), while $24.3 \%$ in flats and $10 \%$ in semi-detached houses.

Table 2: Demographic background of the Respondents

\begin{tabular}{|c|c|c|}
\hline & Number & Percentage $(\%)$ \\
\hline \multicolumn{3}{|l|}{ Race } \\
\hline Libyan & 445 & 92.3 \\
\hline Others & 37 & 7.7 \\
\hline \multicolumn{3}{|l|}{ Age } \\
\hline Under 20 years old & 68 & 14.1 \\
\hline $21-29$ years old & 183 & 38 \\
\hline $30-39$ years old & 165 & 34.2 \\
\hline 40-49 years old & 49 & 10.2 \\
\hline $50-59$ years old & 14 & 2.9 \\
\hline 60 years and above & 3 & 0.6 \\
\hline \multicolumn{3}{|l|}{ Gender } \\
\hline Male & 264 & 54.8 \\
\hline Female & 218 & 45.2 \\
\hline \multicolumn{3}{|l|}{ Education } \\
\hline $\begin{array}{c}\text { Did not attend any } \\
\text { school }\end{array}$ & 20 & 4.1 \\
\hline Primary school & 17 & 3.5 \\
\hline Secondary school & 70 & 14.5 \\
\hline University level & 349 & 72.4 \\
\hline Others & 26 & 5.4 \\
\hline \multicolumn{3}{|l|}{ Occupation } \\
\hline Government & 169 & 35.1 \\
\hline Private & 23 & 4.8 \\
\hline Own Business & 34 & 7.1 \\
\hline Housewife & 22 & 4.6 \\
\hline Student & 205 & 42.5 \\
\hline Unemployed & 29 & 6 \\
\hline \multicolumn{3}{|l|}{ Level of Income } \\
\hline Less than LYD100 & 22 & 4.6 \\
\hline LYD 100 to LYD 199 & 9 & 1.9 \\
\hline LYD 200 to LYD 299 & 10 & 2.1 \\
\hline LYD 300 to LYD 399 & 14 & 2.9 \\
\hline LYD 400 to LYD 499 & 36 & 7.5 \\
\hline LYD 500 to LYD 599 & 39 & 8.1 \\
\hline LYD 600 and above & 127 & 26.3 \\
\hline $\begin{array}{c}\text { Did not have any } \\
\text { income }\end{array}$ & 225 & 46.7 \\
\hline \multicolumn{3}{|l|}{ Type of House } \\
\hline Semi-Detached & 48 & 10 \\
\hline Single- Storey Terrace & 3 & 0.6 \\
\hline Double-Storey Terrace & 7 & 1.4 \\
\hline Flat & 117 & 24.3 \\
\hline Apartment & 307 & 63.7 \\
\hline
\end{tabular}

3.2 Factors that hinder the respondents from participating in SWM The factors that hinder the respondents from participating in SWM to keep the city clean shows in Table (3). Using a five-point scale, ranging from 1 (not very important) to 5 (very important), and the respondents indicated the factors in the table below. Accordingly, the most important factor was the irregular waste collection (mean $=3.88$ ), which was considered important (35.3\%) and very important (32.8\%). Improper disposal of waste collected by the authorities (mean $=3.86$ ) was another factor. Third on the list was the lack of transparency in waste management $($ mean $=3.76)$ [21], asserted that inadequate collection and disposal of SW is a major factor contributing to the spread of gastrointestinal and parasitic diseases, which are caused by the proliferation of insects and rodents.

Table 3: Factors that hinder the respondents from participating in SWM

\begin{tabular}{|l|c|c|c|c|c|c|}
\hline \multirow{2}{*}{ Factors } & \multicolumn{5}{|c|}{ Percentage (\%) } & \multirow{2}{*}{ Mean } \\
\cline { 2 - 7 } & $\mathbf{1}$ & $\mathbf{2}$ & $\mathbf{3}$ & $\mathbf{4}$ & $\mathbf{5}$ & 3.88 \\
\hline Irregular waste collection & 3.5 & 5.8 & 22.6 & 35.3 & 32.8 & 3.76 \\
\hline $\begin{array}{l}\text { Lack of transparency in waste } \\
\text { management }\end{array}$ & 3.1 & 8.3 & 25.7 & 34.9 & 28 & 3.76 \\
\hline $\begin{array}{l}\text { Improper disposal of waste } \\
\text { collected by waste collecting } \\
\text { authontues }\end{array}$ & 5.6 & 6.6 & 21 & 29.9 & 36.9 & 3.86 \\
\hline Others, please specify and rate it & & & & & & \\
\hline
\end{tabular}

3.3. Awareness on Laws and Regulations Implemented Concerning Solid Waste

The following section discusses the respondents' awareness of the laws and regulations on SWM in Al-Marj city, Libya which is explained in Table (4). About $76.6 \%$ of the respondents were unaware of the laws and regulations that promote discipline among people who pollute the area. When the respondents were asked about the effects of such laws and regulations, 79\% stated that these contributed to their proper disposal of waste. Moreover, $88.6 \%$ of them supported the laws and regulations prescribing appropriate 
penalty for people who pollute the city. About $68.5 \%$ of the respondents agreed that the appropriate punishments to those who pollute the city should be the following: fine and imprisonment $(16.2 \%)$ and community work (14.5\%).

Table 4: Respondents' Awareness of SWM Laws and Regulations

\begin{tabular}{lcc}
\hline \multicolumn{1}{c}{ Items } & Frequency & Percentage (\%) \\
\hline Awareness of Law/Regulation & & \\
\hline Yes & 113 & 23.4 \\
No & 369 & 76.6 \\
\hline Support the Law/Regulation & & \\
\hline Yes & 427 & 88.6 \\
No & 55 & 11.4 \\
\hline Preference Punishment & & \\
\hline Community work & 70 & 14.5 \\
Fine & 330 & 68.5 \\
Imprisonment & 78 & 16.2 \\
Others & 4 & 0.8 \\
\hline
\end{tabular}

The respondents indicated their awareness on tax payments for the upkeep of the city shows in Table (5). Majority (67.8\%) was unaware of the tax, but almost all respondents (88\%) agreed to pay tax and contribute money to keep the city clean. Similarly, Desa at el [22] stated that Malaysia uses $40 \%$ to $70 \%$ of its taxes on waste management.

Table 5: Respondents' awareness of tax and contribution for SWM

\begin{tabular}{ccc}
\hline Items & Frequency & Percentage (\%) \\
\hline Awareness on Tax & & \\
\hline Yes & 155 & 32.2 \\
No & 327 & 67.8 \\
\hline Support the Tax & & \\
\hline Yes & 424 & 88 \\
No & 58 & 12 \\
\hline
\end{tabular}

3.4. Residents' Perception and Awareness about SWM

The respondents were also asked regarding the sufficiency of public awareness on proper waste disposal shows in Table (6). Using a fivepoint scale, ranging from 1 (strongly disagree) to 5 (strongly agree), the respondents perceived a moderately sufficient public awareness on proper waste disposal (mean $=3.02 ; \mathrm{SD}=1.39$ ). Only $24.9 \%$ agreed and $17 \%$ strongly agreed that public awareness on proper waste disposal was sufficient. Majority of the respondents mentioned that television could be the major source of information on SWM Al-Marj City, Libya. Followed by posters or billboard (20.7\%), and information dissemination (11.6\%). These results are comparable with those of previous studies with [23]. Consequently, the level of consistency between mentality around nature's domain and conduct is influenced by an individual's information and awareness, verbal commitment, and awareness of other's expectations.

Table 6: Respondents' Perception on Public Awareness about SWM

\begin{tabular}{lcc}
\hline \multicolumn{1}{c}{ Options } & Frequency & Percentage (\%) \\
\hline Strongly disagree & 105 & 21.8 \\
Disagree & 63 & 13.1 \\
Nether Agrec nor Disagrce & 112 & 23.2 \\
Agree & 120 & 24.9 \\
Strongly agree & 82 & 17 \\
Mean =3.02 & & \\
SD=1.39 & & \\
\end{tabular}

The respondents were asked regarding their need for information prior to the government's introduction of new policy provided in Table (7). A total of $78.6 \%$ of the respondents agreed to be informed in advance before the government's introduction of a new policy. Moreover, $80.3 \%$ stated that they need to be informed early, that is, less than three months. About $15 \%$ indicated that they need to be informed within three to six months, whereas the rest preferred to be informed within more than six months. A similar issue was noted in Abuja City, Nigeria. Ezeah and Roberts [24] emphasized that MSW management in Abuja City is still at an extremely simple stage. Thus, horrible inefficiencies are regular. Both Fiorillo [25] and Imam et al. [26] concurred that a principal region, in which deficiencies in MSW management in the Abuja City are most obvious, is in the institutional and legitimate systems for SWM. These frameworks should be explored by Abuja City as they are inadequate and require urgent review. Nath [27] mentioned that unplanned policy may lead to have retardation with respect to the sanitary aspect and to the prevalence of diseases, such as malaria.

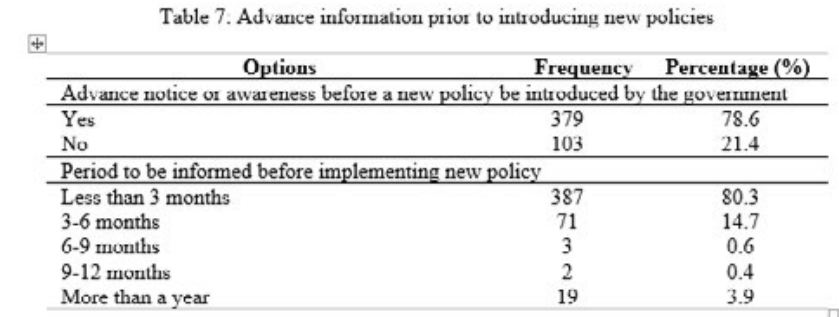

3.5. Residents' opinion regarding emptying of containers in their area The respondents were asked regarding the regular emptying of waste containers in their area. As illustrated in Figure (3), almost $99 \%$ of the respondents stated that the containers are regularly emptied. This result is in line with one stand in the literature [20].

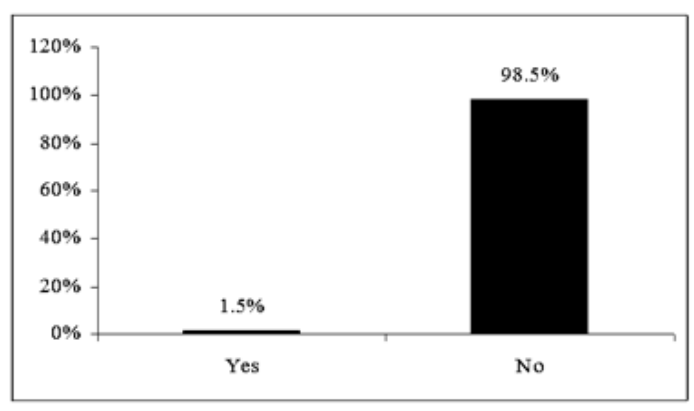

Fig 3. Residents' opinion on the emptying of containers in their area

3.6. Respondents' Perception on the Schedule of Emptying Waste Containers In figure (4) shows lack of containers was indicated by $68 \%$ of the respondent, the containers were unloaded less that $10 \%$ of the time. The highest was "every three days" (9.5\%), followed by "daily" (6.8\%), and "day after day" (4.1\%).

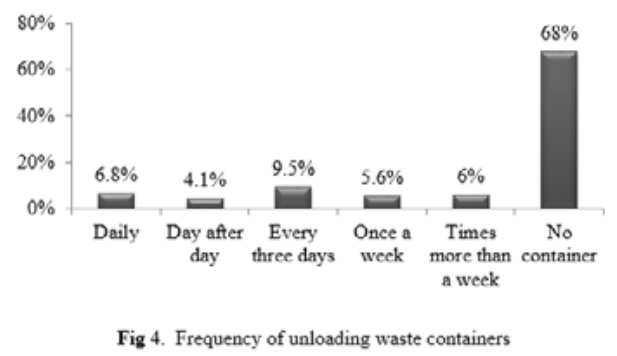

3.7. Sanitation around Waste Containers in the City

The figure (5) presents the poor satisfaction $(77.2 \%)$ of the respondents toward the sanitation around waste containers. A number of respondents described the sanitation condition as very poor (8.5\%), and only $14.3 \%$ indicated satisfaction. Results of the one-way ANOVA revealed in Table (8) that only accommodation ( $\mathrm{p}$-value $=0.019 ;<0.05)$ was significant toward the description of the sanitation around waste containers. Few conducted studies by [12] had reached similar observation. Therefore, it can be said here that type of accommodation plays a big role with the sanitation around waste containers.

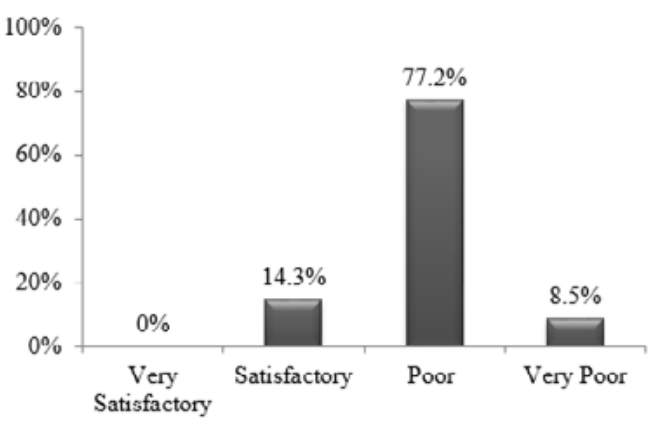

Fig 5. Satisfaction level on the sanitation around waste containers 
solid waste disposal.

\begin{tabular}{|c|c|c|}
\hline \multicolumn{3}{|c|}{ around the Waste Container } \\
\hline Description & $\mathbf{F}$ & $P$-value \\
\hline Citizen & 1.871 & 0.155 (NS) \\
\hline Age & 0.048 & 0.953 (NS) \\
\hline Gender & 1.109 & 0.331 (NS) \\
\hline Education Level & 0.700 & 0.497 (NS) \\
\hline Occupation & 0.663 & 0.516 (NS) \\
\hline Income & 0.985 & 0.374 (NS) \\
\hline Accommodation & 3.985 & $0.019 *(S)$ \\
\hline
\end{tabular}

3.8. Filling up Containers with Solid Wastes

The respondents were asked regarding the tendency of the container to be filled up with waste. As illustrated in the figure (6), among the respondents, $46.9 \%, 30.5 \%$, and $22.6 \%$ stated the containers were filled with waste, occasionally full, and not full, respectively. The possibility of the containers to be full of waste was due to their limited availability, as reflected on the other figures. As shown in Table (9) the demographic background, analysed through the chi-square test, indicated that educational level ( $\mathrm{p}$-value = 0.016 ; $<0.05$ ) and income ( $\mathrm{p}$-value $=0.007 ;<0.05$ ) were the only variables with positive significance toward the description of possibility of the SW containers being filled up.
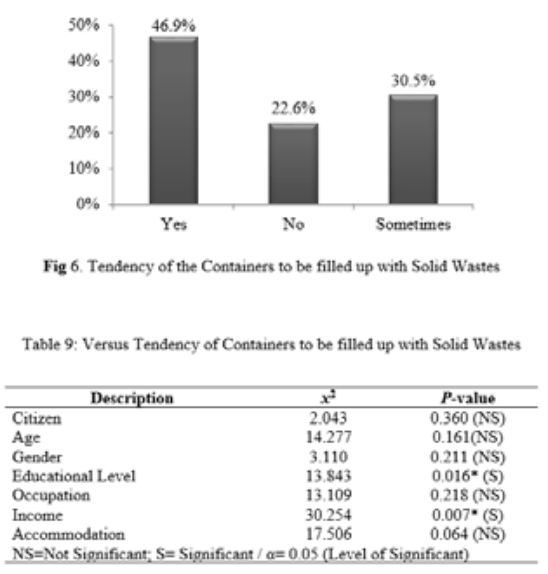

3.9. Solid Waste Disposal in Al-Marj City

Solid waste disposal was evaluated based on the distance between the solid waste disposal site and the respondents' accommodation, the solid waste dump's maintenance and sanitation, and the nuisance experienced in relation to solid waste disposal. The figure (7) shows that $54.3 \%$ of the respondents' accommodation was far from the solid waste disposal and that $23.9 \%$ was close to it. By contrast, $21.8 \%$ had no idea about the proximity of the nearest waste disposal site to their accommodation. In a study conducted by [28] on the city of Ibadan in Nigeria, the city is found to be polluted with decaying solid waste which is found everywhere in the city including the streets drains and water bodies due to unavailability of SW facilities and lack of maintenance.

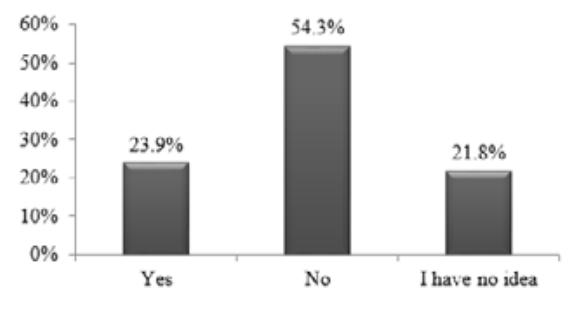

Fig 7. Solid waste dump adjacent to respondents 'accommodation

Demographic background reflected on the selection of distance of the solid waste disposal showed a significant value on gender ( $\mathrm{p}$-value $=0.018$; $<0.05$ ), income ( $\mathrm{p}$-value $=0.015 ;<0.05)$, and accommodation ( $\mathrm{p}$-value $=$ $0.020 ;<0.05)$. Figure (7) revealed that awareness among the respondents on the maintenance level of the waste dump was extremely low. Among the respondents, $74.9 \%$ indicated unawareness of waste dump maintenance while in the Table (10) proven that such interpretation in accord with findings of $[23,29]$ who found that demographic factors have strong significant relationships with the awareness on the maintenance level of the
Table 10: Demographic Background versus Solid Waste Dumping Adjacent to Respondents' Residence

\begin{tabular}{ccc}
\hline Description & $\mathbf{x}^{2}$ & $\boldsymbol{P}$-value \\
\hline Citizen & 1.859 & 0.395 (NS) \\
Age & 10.747 & 0.377 (NS) \\
Gender & 7.999 & 0.018 (S)* \\
Educational Level & 11.528 & $0.174($ NS) \\
Occupation & 13.861 & $0.179(\mathrm{NS})$ \\
Income level & 27.867 & $0.015(\mathrm{~S})^{*}$ \\
Accommodation & 21.138 & 0.020 (S)* \\
NS=Not Significant; S= Significant $/ \boldsymbol{\alpha}=0.05$ (Level of Significant) \\
\hline
\end{tabular}

3.10. Solid Waste Dumping Method

The solid waste disposal method was likewise explored in this study. Figure (8) shows that the respondents dispose of their solid waste in bushes, roadsides, or even drainage systems $(38 \%)$, by burning $(31.3 \%)$, and through incineration $(2.7 \%)$. However, $21.8 \%$ of the respondents did not answer this item.

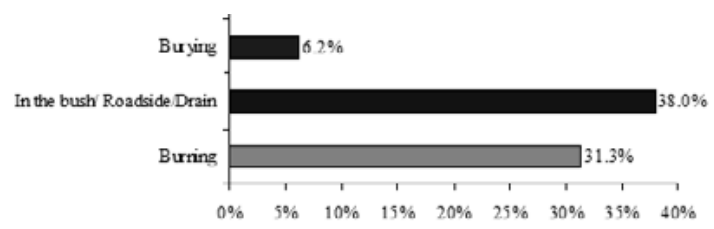

3.11. Perception and Knowledge on the Practice of Solid Wastes Recycling The awareness of residents on recycling of solid wastes in the city of Al-Marj showed that $96.9 \%$ of the respondents were not aware of recycling solid waste program, which was very disappointing. This enormous ignorance could be due to the lack of awareness campaigns on recycling through media, communication and community activities. Read and Evison [30] proved that such campaigns and communication with the public on waste matters encourages individuals to recycle, manage recyclables as well as shows the commitment of the local authority to recycling. In this study, a list of sources that may make the residents aware of such recycling program were included in the survey. The results showed that only $3.3 \%$ of the participants learned about recycling through television, $0.4 \%$ from reading national newspaper, and only $0.2 \%$ obtained information from local newspapers or radio. The success of any solid wastes management plan relies on participation and cooperation of the public. Individual participation is the base of any recycling programs, despite the difference in procedural or hierarchical structures.

\section{Conclusion}

Authorities in charge of solid waste management in the city lack experience and effective practices in the collection, transportation, and disposal of waste. Local authorities still utilize the traditional methods of collection and transport of waste; waste is randomly disposed in an unsanitary open dumping area where no health standards are enforced. Authorities dispose waste without prior analysis of population increase and urbanization in the outskirts of the city; the waste collection process in the entire city is clearly not well implemented. Solid waste management in the city is improper and poor. Vehicles are not in good condition and require maintenance. The general waste disposal situation in the city also ranged from poor to very poor. The majority of the residents in the city believed that recycling solid waste is a very important activity; however, their attitude toward this activity was found to be negative. The residents did not recycle nor were they involved in such activities. Most residents do not know how to recycle solid waste; some of them did not even know the items that can be recycled. Moreover, no recycling facilities are available in living areas although many facilities are listed as available. The results also show that many factors can motivate the residents of Al-Marj to participate in recycling and solid waste management; amongst these factors, "reducing the amount of rubbish disposal" is the first choice of participants as an important motivational factor followed by reduces pollution" and "saves space in waste bins at homes.

Acknowledgements

Marlia Mohd Hanafiah was partly funded by the Ministry of Education grant (FRGS/2/2013/STWN01/UKM/03/1) and UKM TopDown research grant (TD-2014-012).

\section{References}

[1] J. McAllister, Factors Influencing Solid-Waste Management in the Developing World, All Graduate Plan B and other Reports, 528 (2015). DOI: http://digitalcommons.

usu.edu/gradreports/528.

[2] A. Milea, Waste as a Social Dilemma. Issues of Social and Environmental Justice and the Role of Residents in Municipal Solid Waste 
Management, Delhi, India. 2009.

[3] M. Kojima, Economic integration and recycling in Asia: an interim report, Chosakenkyu Hokokusho, Institute of Developing Economies, 2011. [4] Sanitation Connection, HealthCare Waste Management: Annual report, 2002.

[5] P. Schübeler, J. Christen, K. Wehrle, Conceptual framework for municipal solid waste management in low-income countries (Vol. 9), SKAT (Swiss Center for Development Cooperation), 1996.

[6] C. Bartone, Strategies for improving municipal solid waste management: lessons from world bank lending and CWG activities, in Workshop on Planning for Sustainable and Integrated Solid Waste Management, Manila. 2000, pp. 18-22.

[7] R. Gerlagh, P.V. Beukering, M. Verma, P,P, Yadav, P. Pandey, Integrated Modelling of Solid Waste in India, Collaborative research in the economics of environment and development (CREED), 1999.

[8] S. Sarkar, Autonomy, self-rule and community in Darjeeling Hills: a review of Gorkhaland territorial administration (GTA), 2012. Available at SSRN 2038225.

[9] S., Chakrabarti, P. Sarkhel, Economics of solid waste management: A survey of existing literature. Economic Research Unit Indian Statistical Institute, India. 2003.

[10] M. Medina, Globalization, development, and municipal solid waste management in third world cities, Institute of Advance Studies, Mexico. 2002, pp. 1-23.

[11] H. Ogawa, Sustainable solid waste management in developing countries: waste management. Imiesa, 33/9 (2008), 57-9.

[12] K. Gebrie, Management of Domestic Solid Waste in Bahirdar Town: Operational Analysis and Assessment of Constraints that Affect Solid Waste Management, Addis Ababa, Ethiopia, 2009.

[13] C. Zurbrugg, Urban solid waste management in low-income countries of Asia: How to cope with the garbage crisis. Presented for: Scientific Committee on Problems of the Environment (SCOPE) Urban Solid Waste Management Review Session, Durban, South Africa, 2002, p. 1-3.

[14] Cunningham, Principles of Environmental Science Inquiry and Applications (4th ed.), McGraw Hill International Edition, USA, 2008.

[15] C.P. Vencatasawmy, M. Öhman, T.A. Brännström, Survey of recycling behaviour in households in Kiruna, Sweden, Waste Management and Research 18/6 (2000), 545-556.

[16] N.A. Agajam, Managing the Landfill Sites between the Reality and Modernity: A case Study from Ganfoudah Disposal Site in Benghazi city, Department of science and Environmental Engineering, Academic of Postgraduate Studies, Benghazi city, Libya, Unpublished MS.c Thesis, 2005.

[17] A.M. Damghani, G. Savarypour, E. Zand, R. Deihimfard, Municipal solid waste management in Tehran: Current practices, opportunities and challenges. Journal of Waste management 28/5, (2008), 929-934.

[18] D. Suocheng, K.W. Tong, W. Yuping, Municipal solid waste management in China: using commercial management to solve a growing problem, Utilities Policy 10/1 (2001), 7-11.

[19] S.S. Nas, A. Bayram, Municipal solid waste characteristics and management in Gümüşhane, Turkey, Waste management 28/12 (2008), 2435-2442.

[20] A. Omran, A. Mahmood, H.A. Aziz, Current Practice of Solid Waste Management in Malaysia and its Disposal, Environmental Engineering \& Management Journal (EEMJ) 6/4 (2007), 295-300.

[21] M. Purcell, W.L. Magette, Attitudes and behavior towards waste management in the Dublin, Ireland region, Waste management, 30/10 (2010), 1997-2006.

[22] A. Desa, N.B. Kadir, F. Yusooff, Waste education and awareness strategy: towards solid waste management (SWM) program at UKM, Procedia-Social and Behavioral Sciences 59 (2012), 47-50.

[23] A. Omran, Attitude of Malaysian on Recycling of Solid Wastes in Malaysia case Studies in the Major towns of the East Coast and North Malaysia, PhD Unpublished Thesis, Universiti Sains Malaysia, Pulau Pinang, Malaysia, 2008.

[24] C. Ezeah, C.L. Roberts, Analysis of barriers and success factors affecting the adoption of sustainable management of municipal solid waste in Nigeria, Journal of Environmental management 103 (2012), 9-14.

[25] D. Fiorillo, Household waste recycling: national survey evidence from Italy, Journal of Environmental Planning and Management 56/8 (2013), 1125-1151.

[26] A. Imam, B. Mohammed, D.C. Wilson, C.R. Cheeseman, Solid waste management in Abuja, Nigeria, Waste management 28/2 (2008), 468-472.

[27] K.J. Nath, Home hygiene and environmental sanitation: a country situation analysis for India, International Journal of Environmental Health Research 13/sup1 (2003), S19-28.

[28] G. Kanat, A. Demir, B. Ozkaya, M.S. Bilgili, Addressing the operational problems in a composting and recycling plant, Waste Management 26/12 (2006), 1384-1391.

[29] S.F. Sidique, S.V. Joshi, F. Lupi, Factors influencing the rate of recycling: An analysis of Minnesota counties, Resources, Conservation and Recycling 28/54 (2010), 242-249.

[30] A.D. Read, T. Evison, Local authority recycling and waste awareness publicity/promotion, Journal of Resources, conservation and recycling, 32/3, (2001), 275-291. 